\title{
Perspectives
}

\section{Strategies for the Identification of Icosahedral Virus Receptors}

\author{
Dorsey M. Bass* and Harry B. Greenberg ${ }^{* 5}$ \\ Departments of ${ }^{*}$ Pediatrics, ${ }^{\ddagger}$ Medicine, and ${ }^{\$}$ Microbiology and Immunology, Stanford University, Stanford, California 94305 ; \\ and ${ }^{\ddagger}$ Palo Alto Veterans Administration Hospital, Palo Alto, California 94304
}

The first step in virus infection of a host cell is attachment to the cell plasma membrane. This necessary but not always sufficient event in cell infection is important for several reasons. Specific receptor expression can be an important determinant of host range and cell and tissue tropism of a virus, although productive infection may be regulated at many other stages in viral replication as well. As an initial step in infection, virus binding offers an opportunity for chemical or immunologic intervention before the viral genome has reached relative sanctuary within the cell. Finally, characterization of viral receptors can lead to the identification of new cell surface molecules whose normal function can then be determined.

A variety of strategies has been employed to identify and characterize specific viral receptors. Most of these studies, however, have not definitively demonstrated that the putative receptor actually mediates infection of the cell. To fully establish that an interaction between a virus and a presumed receptor has biologic significance, it is necessary to demonstrate that such an interaction can initiate viral infection of the cell. The most stringent test of biologic significance is the transformation of receptor-negative nonpermissive cells to a permissive phenotype by molecularly engineered transfer of genetic material encoding a putative receptor. Recently these stringent criteria have been met for a small icosahedral virus, poliovirus (1) as well as for the enveloped viruses HIV (2) and Maloney murine leukemia virus (3).

This review will concentrate on recent progress in the study of cell receptors for nonenveloped, icosahedral viruses (see Table I). Icosahedral viruses present unique questions concerning the early events of viral infection, especially those of viral entry. The review will not be exhaustive but will use selected examples to emphasize the methodologies and experimental strategies which have made this progress possible. Several more comprehensive recent reviews of viral receptors are available $(4,5)$.

Although viral receptors have long been a topic of interest, until recently progress in this area has been rather slow for a number of reasons. Most purified virus preparations contain a high ratio ( $>100: 1)$ of total particles to infectious units and there are not clear biochemical, immunologic, or morphologic

Address correspondence to Harry B. Greenberg, M.D., Stanford University School of Medicine, Division of Gastroenterology, Room 5069, Stanford, CA 94305-5100.

Received for publication 8 July 1991 and in revised form 7 August 1991.

J. Clin. Invest.

(c) The American Society for Clinical Investigation, Inc.

0021-9738/92/01/0003/07 \$2.00

Volume 89, January 1992, 3-9 criteria to distinguish which particles are truly infectious. Thus, ultrastructural and biochemical observations of virus cell interactions may be irrelevant because most of the virions examined are not infectious. Furthermore, cell receptors for viruses are often relatively scarce, ranging from $10^{3}$ to $10^{5} / \mathrm{cell}$. The affinity of a single receptor for a virus may be quite low, particularly when that receptor has been removed from the plasma membrane. Additionally, receptors may vary greatly for different serotypes of the same genus, such as the rhinoviruses (6). Viruses may bind to very different molecules in different cells or to different molecules on the same cells. Receptors may be shared by unrelated viruses such as adenovirus and coxsackie B viruses (7). Viruses may attach to cells via ubiquitous surface components such as sialic acid as shown for influenza (8) and proposed for reovirus (9) and polyomavirus (10). Finally, interactions between viruses and cell membranes may be much more complex than simple models based on the interactions of peptide ligands with receptors. Multiple viral components may interact with several plasma membrane components to mediate productive viral binding and penetration.

\section{Viral attachment proteins}

Although the viral components which mediate attachment to cells (VAPs) ${ }^{1}$ are not the subject of this review, a brief synopsis of our current knowledge of these molecules is appropriate in order to better understand the virus-cell interaction. VAPs for icosahedral viruses may be tentatively separated into two groups. The first group, consisting of most but not all picornavirus VAPs, is hypothesized to attach to target cells via a cleft or "canyon" on the virus surface which is defined by multiple viral capsid peptides. An increasing body of evidence reviewed by Rossman (11) supports this model. It has been suggested that the steric inaccessibility to antibodies of the highly conserved VAP cleft residues is a mechanism by which the virus avoids immune attack. The second major group of VAPs features a surface projection or spike as the binding structure. The reovirus hemagglutinin $\sigma 1$, the adenovirus fiber protein, and probably the rotavirus vp4 protein function in this fashion. For these viruses it can be hypothesized that the extended VAP enhances the binding efficiency of the virus. Some icosahedral viruses do not fit into this simple classification, however. For example, foot-and-mouth disease virus (FMDV) is a picornavirus which has no canyons, pits, or large surface projections (12). It appears that FMDV attachment is mediated by portion of VP1 which forms a disordered loop. This loop contains an RGD amino acid sequence common to many extracellular ligands for binding to cell surface integrin molecules. RGD con-

1. Abbreviations used in this paper: VAP, viral attachment protein; VRC, virus-receptor complex. 
Table I. Summary of Current Information Characterizing VAP and Viral Cell Surface Receptors

\begin{tabular}{|c|c|c|}
\hline Virus & VAP & Receptor \\
\hline Poliovirus & “Canyon"? & Immunoglobulin superfamily member \\
\hline Rhinovirus (major group) & "Canyon" & ICAM-1 (immunoglobulin superfamily member) \\
\hline Rhinovirus (minor group) & "Canyon"? & $120 \mathrm{kD}$ glycoprotein on HeLa cells \\
\hline Coxsackievirus A & "Canyon"? & Some members use ICAM-1 \\
\hline Coxsackievirus B & "Canyon"? & 49-kD glycoprotein \\
\hline Foot-and-mouth disease & RGD sequences on VP1 (surface "loop" projection) & Integrin superfamily member(s)? \\
\hline Reovirus & $\sigma 1$ surface protein "projection" & $\begin{array}{l}\beta \text {-Adrenergic receptor for serotype } 3 \text { ? Also sialic acid } \\
\text { containing glycoproteins for serotypes } 1 \text { and } 3\end{array}$ \\
\hline Rotavirus (animal) & vp4 surface protein “projection”? & Sialic acid containing glycoproteins \\
\hline Rotavirus (human) & vp4 surface protein "projection"? & Sialic acid independent binding and infection \\
\hline Bluetongue & P2 outer capsid protein & ??????? \\
\hline Adenovirus & $\begin{array}{l}\text { Fiber protein surface projection possibly followed by } \\
\text { penton base interaction }\end{array}$ & 42-kD glycoprotein? \\
\hline Polyomavirus & VP1 outer capsid protein & 50-kD glycoprotein? \\
\hline
\end{tabular}

? signifies that the information is incomplete, controversial, or not confirmed.

taining peptides are able to compete with FMDV virions for binding to cells (13). It is not presently known whether the "canyon" type VAPs and the "projection" type VAPs bind to fundamentally different types of molecules on cell surfaces. The difference in structures, however, might imply that different types of receptors are involved.

\section{Morphologic studies}

Many of the earliest attempts to characterize viral receptors involved morphologic studies. In the 1960 s, electron microscopy of virus infected tissue culture cells was a common method of studying early virus-cell interactions (reviewed in reference 14). Given the caveat mentioned above regarding the high particle to infectious unit ratios, such studies must be interpreted with caution. Morphologic approaches have been particularly useful for answering questions regarding localization of virus binding sites either on polarized cells or on a specific cell type in a complex tissue. Electron microscopy has been used to show preferential binding of reovirus serotype 1 to the basolateral domain of enterocytes (15) and of SV40 virions to the apical surface of polarized epithelial cells (16). In in vivo studies of reovirus binding to intestinal epithelium, Wolf et al. showed that serotype 1 reovirus binds almost exclusively to specialized epithelial cells overlying Peyer's patches known as $\mathrm{M}$ cells and not to the adjacent enterocytes (17).

\section{Kinetic studies}

Another early approach to the study of viral receptors utilizes classical binding kinetics to quantify and characterize receptor distribution. In typical studies of this type, radiolabeled virus at various concentrations is allowed to adsorb to target cells or membrane preparations with or without unlabeled competing virus. Results can then be analyzed to determine the number and class of receptors per cell, affinity constants, cooperativity, and whether the receptor is shared by other viruses. Furthermore, treatment of target cells with glycosidases, proteases, or lipases before binding virus may reveal basic biochemical information about the structure of cellular receptors. This type of kinetic approach does not usually take into account the high particle to infectious unit ratios. Also, the ability to bind virus in a saturable fashion does not necessarily correlate with permissivity of a cell to infection $(18,19)$. In some cases, little or no binding of virus to cells can be detected in binding assays yet productive infection still occurs (20).

Early kinetic studies of picornavirus binding demonstrated that cellular receptor sites were salt-dependent, saturable, and protease-sensitive (reviewed in reference 4). Heterologous competition binding studies among different picornaviruses demonstrated that picornaviruses could be assigned to receptor "families" (7). All three serotypes of poliovirus share a single distinct receptor (21). Poliovirus bound only to cells of primate origin and not to murine cell lines (22). The demonstration that transfection with poliovirus RNA leads to productive infection in receptor-deficient murine cells supported the concept that viral binding to cell surface receptors may be a major determinant of host range and tissue tropism (23). Similar competition studies have been used to divide rhinovirus receptors into two families termed major (91 serotypes) and minor (10 serotypes) $(6,24)$. Similarly, picornavirus receptor families have been described for coxsackie viruses A and B (7), apthoviruses (25), and Theiler's murine encephalomyelitis (EMC) virus (26). Kinetic analysis has demonstrated that some adenoviruses share a cell receptor with coxsackie viruses (7).

Competition kinetic analysis using the three major serotypes of reovirus have also yielded varying results. A single, common receptor for serotypes 1 and 3 was identified on endothelial cells (27) while independent receptors for serotypes 1 and 3 were noted on a pituitary cell line (28), intestinal epithelial cells (29), and on murine L cells (30). Another study showed competition between serotypes 1 and 3 for $L$ cell receptors suggesting a common receptor (31).

Rotavirus receptors have also been characterized by saturation binding studies which demonstrated sialic acid dependent binding of simian SA 11 rotavirus (32). Other studies showed that the reduced binding observed after neuraminidase treatment correlated with reduced infectivity (33). Specific forms of sialic acid appear to be important in simian rhesus rotavirus binding to and infection of cultured human hepatocytes (34). Further studies have shown that human rotaviruses, which unlike most animal isolates do not hemagglutinate human type $\mathrm{O}$ 
erythrocytes, infect MA104 cells independent of sialic acid (35). Thus, at least two "families" of rotavirus receptors appear to exist in MA 104 cells, one sialic acid dependent and one sialic acid independent.

In summary, although kinetic binding studies have provided useful information about the specificities and general structural features of viral receptors, the descriptive data generated has not lead to the actual isolation or purification of a functional viral receptor. Many of the studies have measured binding rather than infection and hence may not be measuring the biologically relevant interaction.

\section{Biochemical approaches}

Direct purification and biochemical characterization of various icosahedral viral receptors has been one of the most frequent strategies employed to identify these structures. Most purification schemes have utilized the VAP in some form of affinity purification strategy in an attempt to identify and characterize specific cell surface receptors. Thus purified virus or viral attachment protein is allowed to bind to cell membranes either in situ on cell monolayers, in solution after detergent extraction from cells, or bound to some form of solid phase matrix. The advantage of this type of approach is that it may allow for the actual isolation and purification of specific cell membrane molecules involved in viral attachment. The problems with these strategies are similar to those discussed above: (a) poor affinity for monomeric virus-receptor complexes compared to the multivalent binding which functions in vivo, and (b) the need to correlate productive infection with binding to a given entity.

Perhaps the most success in use of these biochemical methods has been reported by Crowell and co-workers in their studies of coxsackie B virus receptors (36-41). Initially, a solidphase assay for solubilized receptor was developed on microtiter plates (36) and used to determine that the receptor was a glycoprotein with an apparent molecular weight of $275 \mathrm{kD}$ by size exclusion chromatography (37). The high affinity of the coxsackie $B$ receptor for the virus allowed for the copurification of the virus with detergent solubilized receptor by differential centrifugation (38). This purified virus-receptor complex (VRC) was iodinated and analyzed by SDS-PAGE. The VRC consists of viral capsid proteins and an $\sim 50-\mathrm{kD}$ HeLa cell membrane component termed RP-a. RP-a was used as an immunogen to produce polyclonal and monoclonal anti-receptor antibodies which protected HeLa cells from coxsackie B infection (40). Using similar methodology, a membrane protein similar to RP-a has been identified on a murine $\mathrm{T}$ cell line, YAC 1 (41).

Polyomavirus-receptor complexes are also reported to be stable to detergent treatment and differential centrifugation (42). The cell receptor components of virus-receptor complexes were isolated by immunoprecipitation and identified by SDS-PAGE. Protein bands of 90,50 , and $27 \mathrm{kD}$ were identified. Similar bands were observed when cell membrane extracts were electroblotted to nitrocellulose and probed with radiolabeled polyoma virions. The relationship of these protein components to a previously described $120-\mathrm{kD}$ receptor is unclear (43). Similar biochemical approaches have also been used to identify the minor group receptor for rhinoviruses (44) as well as a putative adenovirus receptor (45).

A more recent modification of the affinity-based biochemical approach to receptor identification has used variations of ligand blotting, sometimes termed virus overlay protein blotting assay (46). In this assay membranes are prepared from cells or tissues, separated by SDS-PAGE, electroblotted to nitrocellulose, and probed with virus. Membrane components which retain high affinity for virus are detected as bands on the nitrocellulose. A major potential drawback to this method is the denaturation of the membrane components which occurs during electrophoresis and blotting. Thus, receptors which function as homo- or heteromultimers are not likely to be identified. On the other hand, the high local concentration of a single receptor present on the nitrocelluose may allow for cooperativity with multivalent virions and increase the sensitivity compared to liquid phase binding assays. Several icosahedral viruses have been studied by this technique including adenovirus $(47)$, rhinovirus $(48)$, reovirus $(27,49)$, and rotavirus $(50,51)$.

To date most of the data obtained with biochemical affinity approaches has not been directly correlated with actual cell infection. Such correlation, as demonstrated by the generation of protective antireceptor antibodies for the group B coxsackieviruses, will be necessary to establish the significance of these types of studies. The biochemical studies are most useful when they permit production of monospecific antibody to the putative receptor or permit determination of specific amino acid sequence of part of the receptor. Such information can then be used to identify receptor on the molecular level.

\section{Immunologic approaches}

Within the last decade, two immunological approaches have been employed in the study of viral receptors: anti-cell surface monoclonal antibodies and antiidiotypes. With both methods antibodies are generated against cell surface epitopes critical for viral binding. Such reagents are generally selected by their ability to block viral attachment and infection. It is of course possible that such antibodies are not directed against the receptor per se but block binding via steric hindrance. However, the utilization of such reagents to identify and subsequently molecularly clone biologically active receptors (see below) indicates that these methods can generate antibodies directed against the actual receptor. Cloning of both the poliovirus and rhinovirus receptors was possible because such immunologic reagents were available.

In the first method, whole target cells or their isolated plasma membranes are used as immunogens for the purpose of generating monoclonal antibodies against cell surface components. Theoretically, cell surface receptors for viruses will be among the surface components which elicit an immune response. The screening of the resultant hybridoma colonies is usually by a cell protection assay in which inhibition of infection by hybridoma supernatents is considered a positive response. A number of investigators have successfully used this approach to isolate $m A b s$ which inhibit viral replication by binding to membrane components. Icosahedral virus receptors successfully identified by this strategy include poliovirus (5254), rhinoviruses (55), and group B coxsackieviruses $(39,40$, 56). In reports to date, specificity of the protection has been striking and usually correlates well with previous competition binding studies. Early success in generating mAbs against polio and the major receptor group of rhinoviruses may be related to the fact that these picornaviruses do not bind to or infect murine cells. Thus, their receptors may have been particularly immunogenic in mice.

Several independent groups have isolated mAbs against the 
poliovirus receptor. Two of the groups isolated mAbs which blocked infection with all three serotypes of polio and no other enteroviruses as expected from previous kinetic binding studies $(52,53)$. These mAbs recognized receptors only on poliovirussusceptible primate cell lines. A more recent report describes a $\mathrm{mAb}$ which protects cells only from poliovirus serotypes 1 and 2 and recognizes a $100-\mathrm{kD}$ protein by western blot (54). The relationship between this putative receptor and those detected by earlier workers remains to be clarified.

A mAb which blocks attachment of the major group of human rhinoviruses was isolated by Colonno and co-workers (55). This antibody protected HeLa cells against 78 of $88 \mathrm{hu}-$ man rhinovirus serotypes tested as well as three serotypes of coxsackie A virus as predicted from earlier competition binding studies. Interestingly, when grown on murine cell lines, the coxsackie A viruses were not inhibited by the mAb, suggesting that viruses may use different receptors for productive binding to different cells. Infection of HeLa cells by a wide variety of other viruses was not effected by treatment with the mAb. Both the antibody and major group rhinoviruses bound to the surface of a variety of human cell lines. The affinity of the mAb for the rhinovirus receptor was apparently quite high because it could effectively displace prebound virus from cells.

Several antireceptor mAbs for group B coxsackie viruses were cell line specific $(39,40,56)$, inhibiting binding and infection on some permissive cell lines but not on others. Thus, again we see that diverse receptors for the same virus may exist on different permissive cell lines. Such receptor diversity seems likely to exist on different cell types in vivo as well. HeLa cells were shown to have two distinct receptors for the group B coxsackieviruses $(39,40)$ but binding to only one of them, termed $\mathrm{HR}$, led to productive infection. The second HeLa receptor, termed HR2, could mediate infection in human rhabdomyosarcoma cells, however. Further elucidation of these enigmatic findings will likely occur when the genes encoding the two receptors have been molecularly cloned.

It is noteworthy that virtually all of the antireceptor antibodies produced to date by this method have been directed against picornavirus receptors. It may be that picornavirus receptors which bind to clefts or canyons in the surface of virions are particularly immunogenic and/or sterically accessible to antibody blockade.

The second immunologic approach to identification of viral receptors has been the use of antiidiotypic antibodies (anti-Id). This methodology is based on the concept that the hypervariable antigen binding sites of immunoglobulins may function themselves as antigens (57). Thus, an antibody (an anti-Id) directed against the binding site of an antibody against an antigen may be structurally equivalent to the original antigen. If the original antigen is the active portion of a VAP, the anti-Id may attach to the cell receptor for the virus in an analogous fashion to the VAP.

Although anti-Ids have been used to identify and study a variety of cell receptors (reviewed in reference 58), the first successful application to virus receptors was the identification of a reovirus receptor (59). This anti-Id was generated against a mAb which neutralized serotype 3 reovirus via its cell attachment protein, $\sigma 1$. Further studies revealed that this anti-Id $\mathrm{mAb}$ partially inhibited reovirus binding to $\mathrm{L}$ cells but did not inhibit infection (60). The mAb recognizes a 67-kD membrane protein which was expressed on many cell types and bore remarkable biochemical resemblance to the $\beta$-adrenergic recep- tor $(61,62)$. Sequencing of the variable regions of the light and heavy chains of the anti-Id revealed areas of homology with the original antigen, $\sigma 1$ (63). Controversy continues, however, over whether the $\beta$-adrenergic receptor is an actual receptor for serotype 3 reovirus $(49,64-67)$.

The antiidiotype strategy has been demonstrated to be feasible for at least one other nonenveloped virus. Polyclonal antiId to a polyomavirus $\mathrm{mAb}$ has been reported to compete with virions for cell receptor sites, protect cells from infection in a dose-dependent fashion, and react predominantly with a 50$\mathrm{kD}$ cell surface protein in western blot and immunoprecipitation (68). To date this antisera has not been used to characterize the polyoma receptor at the molecular level.

In summary, immunologic approaches to identification of virus receptors offer the opportunity to define virus-cell surface interactions on a functional basis. Such approaches appear to be among the most useful for identifying viral receptors at the molecular level.

\section{Molecular/genetic}

Recently techniques of molecular biology have been used to definitively identify and characterize picornavirus receptors. Three separate groups have demonstrated that the major group rhinovirus receptor is ICAM-1, an immunoglobulin superfamily member which functions as a cell adhesion molecule involved in leukocyte adhesion (69-71). In these studies mAbs directed against a putative cellular receptor were used to affinity-purify the receptor protein for amino acid sequencing, thereby revealing the identity of the receptor as ICAM-1 (69, 71). It was further shown that COS cells transfected with the ICAM-1 cDNA were able to bind rhinovirus (70), as were mouse cells transfected with human chromosomal material containing the ICAM-1 gene (71). mAbs directed against ICAM-1 were able to prevent binding and infection of HeLa cells by rhinovirus (70). Furthermore, only those mAbs which inhibited binding of leukocytes to ICAM via LFA (lymphocyte function associated antigen) blocked rhinovirus binding indicating that the two binding sites were in close proximity. Recently, additional studies have used site-directed mutagenesis to construct a soluble form of ICAM- 1 which is expressed and secreted by transfected $\mathrm{CHO}$ cells. Soluble ICAM-1 has been shown to specifically protect HeLa cells from rhinovirus infection by inhibiting viral binding (72). Chimeric and mutant ICAM-1 molecules have been used to map the binding site of rhinovirus to the most external two of five immunoglobulin tandem repeats, overlapping but not identical to the binding site of LFA-1 (73). Similar results were obtained using a panel of mAbs to immunoprecipitate a series of truncated ICAM-1 protein products (74). Notably, expression of ICAM-1 by nonprimate cells has not been shown to be sufficient for productive rhinovirus infection.

A somewhat different strategy was required for cloning of the poliovirus receptor because the anti-receptor $\mathrm{mAb}$ available did not react with solubilized membrane material $(1,75)$. Susceptibility to poliovirus infection was transferred to receptor-negative murine L cells via genomic DNA transformation. Primary and secondary $\mathrm{L}$ cell transformants were detected which were reactive with anti-receptor antibody and susceptible to poliovirus infection. Genomic libraries from the receptor expressing transformants were screened with a probe for the human Alu repeat sequence. A restriction fragment from several overlapping genomic clones thus obtained reacted with 
HeLa cell and the receptor positive transformant cells but not with wild type L cell RNA in Northern blots. This fragment was used to screen cDNA from HeLa cells. Two cDNAs obtained expressed functional receptor when transformed into $\mathrm{L}$ cells, rendering the murine cells susceptible to poliovirus infection. The deduced amino acid sequence of the receptor predicts that the receptor is yet another member of the immunoglobulin superfamily with three disulfide stabilized immunoglobulinlike domains.

The poliovirus binding domain of this molecule has been mapped by expressing deletion mutants and chimeras of poliovirus receptor and ICAM-1 in murine fibroblasts (76). The amino-terminal, outermost immunoglobulinlike domain is both sufficient and necessary for virus binding. When this domain is chimerically expressed with the ICAM-1 carboxy-terminus, including the transmembrane and first three extracellular domains, the receptor is functional and cells expressing this construct become permissive for poliovirus. Interestingly, mRNA for the receptor is found in virtually all human tissues whether or not they bind or are infected by poliovirus (1). Another group reports that four distinct forms of the poliovirus receptor are produced by alternative splicing (77).

Recently, the role of poliovirus receptor expression in the host range and tissue tropism of poliovirus have been addressed by expressing the receptor in bacteria (78) and in transgenic mice $(79,80)$. Portions of the receptor were expressed in Escherichia coli as fusion proteins which were used to generate polyclonal antireceptor sera. These sera were then employed in Western blot analysis of membrane proteins from HeLa cells and a variety of human tissues. Heterogeneous immunoreactive proteins were found in all tissues regardless of their susceptibility to poliovirus in vivo. There were tissue-specific variations in molecular weight, immunoreactivity, and subunit structure of these reactive proteins suggesting that posttranslational modification or alternative splicing might determine whether the proteins were in fact functional as poliovirus receptors. In experiments designed to investigate the host range of poliovirus, transgenic mice expressing the receptor in all tissues were challenged with wild type poliovirus. Intracerebral, intravenous, or intraperitoneal inoculation with virulent strains of poliovirus resulted in typical paralysis in transgenic but not in control animals. Attenuated vaccine strain poliovirus had no effect. Of interest, oral inoculation, the natural route of infection, failed to produce disease, suggesting again that receptor expression is not always the absolute determinant of viral tropism.

A molecular/genetic approach coupled with the availability of antireceptor antibodies has made possible the definitive identification of the receptor for several icosahedral viruses and provides powerful analytic methods to map the functional areas on these molecules. It is likely that these techniques in conjunction with three-dimensional structural data will allow us to understand precisely how viral receptors mediate infection in the near future.

\section{Unanswered questions and future prospects}

Does receptor expression mediate host range restriction and tissue tropism of icosahedral viruses? The attractively simple hypothesis that specificity of receptor-virus interactions govern many facets of viral pathogenesis is now beginning to be tested in a rigorous manner. In tissue culture cells, there are numerous examples of viruses binding to nonpermissive cells which have blocks to viral replication at stages later than binding. For poliovirus it would appear that host range restriction among species may well be mediated by receptor expression while it appears that binding to ICAM-1 is not sufficient to render nonprimate cells permissive for rhinovirus. It must be remembered that the molecular cloning of both picornavirus receptors was facilitated by the narrow host range of these particular viruses. It is far from clear whether tissue tropism is similarly regulated. Undoubtedly multiple factors influence which tissues in an intact organism are susceptible to a virus infection. For example, ICAM-1 is ubiquitously distributed through human tissues, yet only the upper respiratory tract is infected by rhinoviruses, perhaps in part because of the temperature sensitivity and acid lability of rhinoviruses. Similarly the poliovirus receptor appears to have a wide tissue distribution. Other factors may be primarily responsible for tissue tropism. For example, the presence of local extracellular proteases may be crucial determinants of tissue tropism in rotavirus infection (81).

What role do receptors play in viral penetration of the plasma membrane? While substantial progress has been made in the study of enveloped virus penetration across plasma membranes (reviewed in reference 5), very little is known about the pathways for cell entry of the nonenveloped viruses. It seems reasonable that viral receptors and/or other target cell membrane components are involved in this process. Studies employing the poliovirus receptor expressed in insect cells demonstrate that solubilized receptor can induce profound structural alterations in virions rendering them noninfectious (82). Such alterations have been hypothesized to facilitate membrane penetration of cell surface-bound virus by increasing hydrophobicity (83) as well facilitating uncoating of the viral genome (84). It will be interesting to determine whether the ICAM-1 or other viral receptors share such properties. It seems likely that the identification of cell surface receptors will facilitate analysis of viral penetration using reconstituted systems. It remains to be seen whether unique cell surface molecules other than specific receptors will be required for cell entry as opposed to cell binding.

What are the normal functions of cell surface molecules subverted by viruses for use as receptors? Several viral receptors including those for poliovirus, rhinovirus, and HIV are members of the immunoglobulin superfamily. Does this reflect on common structure/function motifs in these molecules or merely the large number of such molecules on cell surfaces? A function of ICAM-1 has been proposed but little is known about the poliovirus receptor. The poliovirus receptor is evidently not essential for cell function in tissue culture as HeLa subclones deficient in expression of the receptor have been described (85). It is likely that molecular cloning of more viral receptors will lead to identification of additional cell surface molecules whose function will need to be explored.

What are the prospects for antiviral therapies based on knowledge about viral receptors? The two most obvious therapies involve blocking virus-receptor interactions with either antireceptor antibodies or with soluble receptor. Additionally, other chemicals or pharmacologics could be developed that specifically block virus binding either at the level of the cell receptor or the VAP. Clinical trials have been reported using mAb directed against the major group rhinovirus receptor (86). Anti-ICAM-1 recombinant murine mAbs have been expressed by bacteria and could be converted to human immunoglobulins to avoid sensitization to murine antibody (87). Soluble 
receptors have been proposed as therapeutic agents for several viral agents including HIV-1 $(88,89)$ and rhinovirus $(72)$. Theoretically viral epitopes (VAPs) which react with specific receptors essential for infection of cells should be highly conserved because mutations in these areas would be lethal. This concept is supported by the fact that mutants to anti-receptor mAbs have not been reported despite specific efforts to detect them (55). However, studies by Kaplan et al. have demonstrated that "VAP" escape mutants do arise under selection with baculovirus-expressed poliovirus receptor (20). Phenotypically the mutants showed reduced binding to target cells but were inhibited fully by $\mathrm{mAb}$ against the cell receptor. Sequencing of the poliovirus receptor escape mutants has shown the mutations to map to two areas on the canyon rim and wall (Racaniello, V. R., personal communication) suggesting that at least some tolerance exists for mutations in the poliovirus VAP. At this point in time it is still unclear whether the hypothesis is correct that selection of mutations in VAP sequences is truly less frequent than selection of mutations in other viral surface epitopes. If correct, reagents that block VAP-receptor interactions have great promise as antivirals because the emergence of resistant strains would be less likely.

\section{Acknowledgments}

The authors would like to thank Dr. Vincent Racaniello for his thoughtful comments on this manuscript.

This work was supported in part by Digestive Disease Center grant DK38707 from the National Institutes of Health.

\section{References}

1. Mendelsohn, C. L., E. Wimmer, and V. R. Racaniello. 1989. Cellular receptor for poliovirus: molecular cloning, nucleotide sequence, and expression of a new member of the immunoglobulin superfamily. Cell. 56:855-865.

2. Maddon, P. J., S. M. Molineaux, D. E. Maddon, K. A. Zimmerman, M. Godfrey, F. W. Alt, L. Chess, and R. Axel. 1987. Structure and expression of the human and mouse T4 genes. Proc. Natl. Acad. Sci. USA. 84:9155-9159.

3. Albritton, L. A., L. Tseng, D. Scadden, and J. M. Cunningham. 1989. A putative maloney murine leukemia virus receptor gene encodes a multiple membrane spanning protein and confers susceptibility to virus infection. Cell. 57:659666.

4. Racaniello, V. R. 1990. Cell receptors for picornaviruses. Curr. Top. Microbiol. Immunol. 161:1-22.

5. Marsh, M., and A. Helenius. 1989. Virus entry into animal cells. Adv. Viral Res. 36:107-151.

6. Abraham, G., and R. J. Colonno. 1984. Many rhinovirus serotypes share the same receptor. $J$. Virol. 51:340-345.

7. Lonberg-Holm, K., R. L. Crowell, and L. Philipson. 1976. Unrelated animal viruses share receptors. Nature (Lond.). 259:679-681.

8. Weis, W., J. H. Brown, S. Cusack, J. C. Paulson, J. J. Skehel, and D. C. Wiley. 1988. Structure of the influenza virus haemagglutinin complexed with its receptor, sialic acid. Nature (Lond.). 333:426-431.

9. Paul, R. W., A. H. Choi, and P. W. Lee. 1989. The alpha-anomeric form of sialic acid is the minimal receptor determinant recognized by reovirus. Virology 172:382-385.

10. Fried, H., L. D. Cahan, and J. C. Paulson. 1981. Polyoma virus recognizes specific sialyloligosaccharide receptors on host cells. Virology. 109:188-198.

11. Rossmann, M. G. 1989. The canyon hypothesis. Hiding the host cell receptor attachment site on a viral surface from immune surveillance. J. Biol. Chem. 264:14587-14590.

12. Acharya, R., E. Fry, D. Stuart, G. Fox, D. Rowlands, and F. Brown. 1989. The three-dimensional structure of foot-and-mouth disease virus at $2.9 \mathrm{~A}$ resolution. Nature (Lond.). 337:709-716.

13. Fox, G., N. R. Parry, P. V. Barnett, P. McGinn, D. J. Rowlands, and F. Brown. 1989. The cell attachment site on foot-and-mouth disease virus include the amino acid sequence RGD (arginine-glycine-aspartic acid). J.' Gen. Virol. 70:625-637.

14. Dales, S. 1973. Early events in cell-animal virus interactions. Bacteriol. Rev. 37:103-135.

15. Bass, D. M., J. S. Trier, R. Dambrouskas, and J. L. Wolf. 1988. Reovirus type 1 infection of small intestinal epithelium in suckling mice and its effect on $\mathbf{M}$ cells. Lab. Invest. 55:226-235.

16. Clayson, E. T., and R. W. Compans. 1988. Entry of simian virus 40 is restricted to apical surfaces of polarized epithelial cells. Mol. Cell Biol. 8:33913396.

17. Wolf, J. L., R. H. Rubin, R. Finberg, R. S. Kauffman, A. H. Sharpe, J. S. Trier, and B. N. Fields. 1981. Intestinal M cells: a pathway for entry of reovirus into the host. Science (Wash. DC). 212:471-473.

18. Donta, S. T., J. D. Shanley, and B. P. Damiano. 1986. Encephalomyocarditis virus can bind to and transfect non-permissive cells. Arch. Virol. 88:301307.

19. Spalholz, B. A., and P. Tattersall. 1983. Interaction of minute virus of mice with differentiated cells: strain-dependent target cell specificity is mediated by intracellular factors. $J$. Virol. 46:937-943.

20. Kaplan, G., D. Peters, and V. R. Racaniello. 1990. Poliovirus mutants resistant to neutralization with soluble cell receptors. Science (Wash. DC). 250:1596-1599.

21. Crowell, R. L. 1963. Specific viral interference in HeLa cell cultures. $J$. Bacteriol. 86:517-523.

22. Holland, J. J., and L. C. McClaren. 1959. The mammalian cell-virus relationship. II. Adsorption, reception, and eclipse. J. Exp. Med. 109:487-503.

23. Holland, J. J., L. C. McLaren, and J. C. Syverton. 1959. The mammalian cell-virus relationship. III. Production of infectious poliovirus by nonprimate cells exposed to poliovirus nucleic acid. Proc. Soc. Exp. Biol. Med. 100:843-845.

24. Uncapher, C. R., C. M. DeWitt, and R. J. Colonno. 1991. The major and minor group receptor families contain all but one human rhinovirus serotype. Virology. 180:814-817.

25. Sekiguchi, K., A. J. Franke, and B. Baxt. 1982. Competition for cellular receptor sites among selected aphthoviruses. Arch. Virol. 74:53-64.

26. Fotiadis, C., D. R. Kilpatrick, and H. L. Lipton. 1991. Comparison of binding characteristics to BHK-21 cells of viruses representing the two Theiler's virus neurovirulence groups. Virology. 182:365-370.

27. Verdin, E. M., G. L. King, and F. E. Maratos. 1989. Characterization of a common high-affinity receptor for reovirus serotypes 1 and 3 on endothelial cells. J. Virol. 63:1318-1325.

28. Maratos, F. E., C. R. Kahn, D. R. Spriggs, and B. N. Fields. 1983. Specific plasma membrane receptors for reovirus on rat pituitary cells in culture. J. Clin. Invest. 72:617-621.

29. Weiner, D. B., K. Girard, W. V. Williams, T. McPhillips, and D. H. Rubin. 1988. Reovirus type 1 and type 3 differ in their binding to isolated intestinal epithelial cells. Microb. Pathog. 5:29-40.

30. Epstein, R. L., M. L. Powers, R. B. Rogart, and H. L. Weiner. 1984. Binding of ${ }^{125} \mathrm{I}$-labeled reovirus to cell surface receptors. Virology. 133:46-55.

31. Lee, P. W. K., E. C. Hayes, and W. K. Joklik. 1981. Protein $\sigma 1$ is the reovirus cell attachment protein. Virology. 108:156-163.

32. Keljo, D. J., and A. K. Smith. 1988. Characterization of binding of simian rotavirus SA-1 1 to cultured epithelial cells. J. Pediatr. Gastroenterol. Nutr. 7:249256.

33. Yolken, R. H., R. Willoughby, S. B. Wee, R. Miskuff, and S. Vonderfecht. 1987. Sialic acid glycoproteins inhibit in vitro and in vivo replication of rotaviruses. J. Clin. Invest. 79:148-154.

34. Schwarz, K. B., T. J. Moore, R. E. J. Willoughby, S. B. Wee, S. L. Vonderfecht, and R. H. Yolken. 1990. Growth of group A rotaviruses in a human liver cell line. Hepatology. 12:638-643.

35. Fukudome, K., O. Yoshie, and T. Konno. 1989. Comparison of human, simian, and bovine rotaviruses for requirement of sialic acid in hemagglutination and cell absorption. Virology. 172:196-205.

36. Krah, D. L., and R. L. Crowell. 1982. A solid phase assay of solubilized HeLa cell receptors for group B coxsackie viruses and polioviruses. Virology. 118:148-156.

37. Krah, D. L., and R. L. Crowell. 1985. Properties of the deoxycholate-solubilized HeLa cell plasma membrane receptor for binding group B coxsackieviruses. J. Virol. 53:867-870.

38. Mapoles, J. E., D. L. Krah, and R. L. Crowell 1985. Purification of a HeLa cell receptor protein for group B coxsackieviruses. J. Virol. 55:560-566.

39. Crowell, R. L., A. K. Field, W. A. Schleif, W. L. Long, R. J. Colonno, J. E. Mapoles, and E. A. Emini. 1986. Monoclonal antibody that inhibits infection of HeLa and rhabdomyosarcoma cells by selected enteroviruses through receptor blockade. J. Virol. 57:438-445.

40. Hsu, K. H., H. K. Lonberg, B. Alstein, and R. L. Crowell. 1988. A monoclonal antibody specific for the cellular receptor for the group B coxsackieviruses. J. Virol. 62:1647-1652.

41. Hsu, K. H., and R. L. Crowell. 1989. Characterization of a YAC-1 mouse cell receptor for group B coxsackieviruses. J. Virol. 63:3105-3108.

42. Marriott, S. J., G. R. Griffith, and R. A. Consigli. 1987. Octyl-beta-D-glucopyranoside extracts polyomavirus receptor moieties from the surfaces of mouse kidney cells. $J$. Virol. 61:375-382.

43. Griffith, G. R., and R. A. Consigli. 1986. Cross-linking of a polyomavirus attachment protein to its mouse kidney cell receptor. J. Virol. 58:773-781. 
44. Mischak, H., C. Neubauer, E. Kuechler, and D. Blaas. 1988. Characteristics of the minor group receptor of human rhinoviruses. Virology. 163:19-25.

45. Svensson, U., R. Persson, and E. Everitt. 1981. Virus receptor interaction in the adenovirus system. I. Identification of virion attachment proteins of the HeLa plasma membrane. J. Virol. 38:70-81.

46. Boyle, J. F., D. G. Weismiller, and K. V. Holmes. 1987. Genetic resistance to mouse hepatitis virus correlates with the absence of virus binding activity on target tissues. J. Virol. 61:185-189.

47. Defer, C., M. T. Belin, B. M. Caillet, and P. Boulanger. 1990. Human adenovirus-host cell interactions: comparative study with members of subgroups B and C. J. Virol. 64:3661-3673.

48. Mischak, H., C. Neubauer, B. Berger, E. Kuechler, and D. Blaas. 1988. Detection of the human rhinovirus minor group receptor on renaturing Western blots. J. Gen. Virol. 69:2653-2661.

49. Choi, A. H. C., R. W. Paul, and P. W. K. Lee. 1990. Reovirus binds to multiple plasma membrane proteins of mouse fibroblast cells. Virology. 178:316320.

50. Bass, D. M., E. Mackow, and H. B. Greenberg. 1991. Identification and partial characterization of rhesus rotavirus binding glycoprotein on murine enterocytes. Virology. 183:602-610.

51. Willoughby, R. E., R. H. Yolken, and R. L. Schnaar. 1990. Rotaviruses specifically bind to the neutral glycosphingolipid asialo-GM1. J. Virol. 64:48304835.

52. Minor, P. D., P. A. Pipkin, D. Hockley, G. C. Schild, and J. W. Almond. 1984. Monoclonal antibodies which block cellular receptors of poliovirus. Virus Res. 1:203-212.

53. Nobis, P., R. Zibirre, G. Meyer, J. Kuhne, G. Warnecke, and G. Koch. 1985. Production of a monoclonal antibody against an epitope on HeLa cells that is the functional poliovirus binding site. J. Gen. Virol. 6:2563-2569.

54. Shepley, M. P., B. Sherry, and H. L. Weiner. 1988. Monoclonal antibody identification of a $100-\mathrm{kDa}$ membrane protein in HeLa cells and human spinal cord involved in poliovirus attachment. Proc. Natl. Acad. Sci. USA. 85:77437747.

55. Colonno, R. J., P. L. Callahan, and W. J. Long. 1986. Isolation of a monoclonal antibody that blocks attachment of the major group of human rhinoviruses. J. Virol. 57:7-12.

56. Campbell, B. A., and C. E. Cords. 1983. Monoclonal antibodies which inhibit attachment of group B coxsackieviruses. J. Virol. 48:561-564.

57. Jerne, N. K. 1974. Towards a network theory of the immune system. Ann. Immunol. 125:373-387.

58. Gaulton, G. N., M. S. Co, H. D. Royer, and M. I. Greene. 1984. Anti-idiotypic antibodies as probes of cell surface receptors. Mol. Cell. Biochem. 65:5-21.

59. Noseworthy, J. H., B. N. Fields, M. A. Dichter, C. Sobotka, E. Pizer, L. L. Perry, J. T. Nepom, and M. I. Greene. 1983. Cell receptors for the mammalian reovirus. I. Syngeneic monoclonal anti-idiotypic antibody identifies a cell surface receptor for reovirus. J. Immunol. 131:2533-2538.

60. Kauffman, R. S., J. H. Noseworthy, J. T. Nepom, R. Finberg, B. N. Fields, and M. I. Green. 1983. Cell receptors for the mammalian reovirus. II. Monoclonal antiidiotype blocks viral binding to cells. J. Immunol. 131:2539-2541.

61. Co, M. S., G. N. Gaulton, B. N. Fields, and M. I. Greene. 1985. Isolation and biochemical characterization of the mammalian reovirus type 3 cell-surface receptor. Proc. Natl. Acad. Sci. USA. 82:1494-1498.

62. Co, M. S., G. N. Gaulton, A. Tominaga, C. J. Homcy, B. N. Fields, and M. I. Greene. 1985. Structural similarities between the mammalian beta-adrenergic and reovirus type 3 receptors. Proc. Natl. Acad. Sci. USA. 82:5315-5318.

63. Bruck, C., M. S. Co, M. Slaoui, G. N. Gaulton, T. Smith, B. N. Fields, J. I. Mullins, and M. I. Greene. 1986. Nucleic acid sequence of an internal imagebearing monoclonal anti-idiotype and its comparison to the sequence of the external antigen. Proc. Natl. Acad. Sci. USA. 83:6578-6582.

64. Choi, A. H., and P. W. Lee. 1988. Does the beta-adrenergic receptor function as a reovirus receptor? Virology. 163:191-197.

65. Donta, S. T., and J. D. Shanley. 1990. Reovirus type 3 binds to antagonist domains of the beta-adrenergic receptor. J. Virol. 64:639-641.

66. Liu, J., M. S. Co, and M. I. Greene. 1988. Reovirus type 3 and $\left.{ }^{[25} \mathrm{I}\right]-$ iodocyanopindolol bind to distinct domains on the beta-adrenergic like receptor. Immunol. Res. 7:232-238.

67. Sawutz, D. G., D. R. Bassel, and C. J. Homcy. 1987. High affinity binding of reovirus type 3 to cells that lack beta adrenergic receptor activity. Life Sci. 40:399-406.
68. Marriott, S. J., D. J. Roeder, and R. A. Consigli. 1987. Anti-idiotypic antibodies to a polyomavirus monoclonal antibody recognize cell surface components of mouse kidney cells and prevent polyomavirus infection. J. Virol. 61:2747-2753.

69. Tomassini, J. E., D. Graham, C. M. DeWitt, D. W. Lineberger, J. A. Rodkey, and R. J. Colonno. 1989. cDNA cloning reveals that the major group rhinovirus receptor on HeLa cells is intercellular adhesion molecule 1. Proc. Natl. Acad. Sci. USA. 86:4907-4911.

70. Staunton, D. E., V. J. Merluzzi, R. Rothlein, R. Barton, S. D. Marlin, and T. A. Springer. 1989. A cell adhesion molecule, ICAM-1, is the major surface receptor for rhinoviruses. Cell. 56:849-853.

71. Greve, J. M., G. Davis, A. M. Meyer, C. P. Forte, S. C. Yost, C. W. Marlor, M. E. Kamarck, and A. McClelland. 1989. The major human rhinovirus receptor is ICAM-1. Cell. 56:839-847.

72. Marlin, S. D., D. E. Staunton, T. A. Springer, C. Stratowa, W. Sommergruber, and V. J. Merluzzi. 1990. A soluble form of intercellular adhesion molecule-1 inhibits rhinovirus infection. Nature (Lond.). 344:70-72.

73. Staunton, D. E., M. L. Dustin, H. P. Erickson, and T. A. Springer. 1990 The arrangement of the immunoglobulin-like domains of ICAM- 1 and the binding sites for LFA-1 and rhinovirus. Cell. 61:243-254.

74. Lineberger, D. W., D. J. Graham, J. E. Tomassini, and R. J. Colonno. 1990. Antibodies that block rhinovirus attachment map to domain 1 of the major group receptor. $J$. Virol. 64:2582-2587.

75. Mendelsohn, C., B. Johnson, K. A. Lionetti, P. Nobis, E. Wimmer, and V. R. Racaniello. 1986. Transformation of a human poliovirus receptor gene into mouse cells. Proc. Natl. Acad. Sci. USA. 83:7845-7849.

76. Selinca, H.-C., A. Zibert, and E. Wimmer. 1991. Poliovirus can enter and infect mammalian cells by way of an intercellular adhesion molecule 1 pathway. Proc. Natl. Acad. Sci. USA. 88:3598-3602.

77. Koike, S., H. Horie, I. Ise, A. Okitsu, M. Yoshida, N. lizuka, K. Takeuchi, T. Takegami, and A. Nomoto. 1990. The poliovirus receptor protein is produced both as membrane-bound and secreted forms. EMBO (Eur. Mol. Biol. Organ.) J. 9:3217-3224.

78. Freistadt, M. S., G. Kaplan, and V. R. Racaniello. 1990. Heterogeneous expression of poliovirus receptor-related proteins in human cells and tissues. Mol. Cell. Biol. 10:5700-5706.

79. Ren, R. B., F. Costantini, E. J. Gorgacz, J. J. Lee, and V. R. Racaniello. 1990. Transgenic mice expressing a human poliovirus receptor: a new model for poliomyelitis. Cell. 63:353-362.

80. Koike, S., C. Taya, T. Kurata, S. Abe, I. Ise, H. Yonekawa, and A. Nomoto. 1991. Transgenic mice susceptible to poliovirus. Proc. Natl. Acad. Sci. USA. 88:951-955.

81. Vonderfecht, S. L., R. L. Miskuff, S. B. Wee, S. Sato, R. R. Tidwell, J. D. Geratz, and R. H. Yolken. 1988. Protease inhibitors suppress the in vitro and in vivo replication of rotavirus. J. Clin. Invest. 82:2011-2016.

82. Kaplan, G., M. S. Freistadt, and V. R. Racaniello. 1990. Neutralization of poliovirus by cell receptors expressed in insect cells. $J$. Virol. 64:4697-4702.

83. Fricks, C. E., and J. M. Hogle. 1990. Cell-induced conformational change in poliovirus: externalization of the amino terminus of vpl is responsible for liposome binding. J. Virol. 64:1934-1943.

84. Gromeier, M., and K. Wetz. 1990. Kinetics of poliovirus uncoating in HeLa cells in a nonacidic environment. J. Virol. 64:3590-3597.

85. Kaplan, G., and V. R. Racaniello. 1991. Down regulation of poliovirus receptor RNA in HeLa cells resistant to poliovirus infection. J. Virol. 65:18291835.

86. Hayden, F. G., J. J. Gwaltney, and R. J. Colonno. 1988. Modification of experimental rhinovirus colds by receptor blockade. Antiviral Res. 9:233-247.

87. Condra, J. H., V. V. Sardana, J. E. Tomassini, A. J. Schlabach, M. E. Davies, D. W. Lineberger, D. J. Graham, L. Gotlib, and R. J. Colonno. 1990. Bacterial expression of antibody fragments that block human rhinovirus infection of cultured cells. J. Biol. Chem. 265:2292-2295.

88. Berger, E. A., T. R. Fuerst, and B. Moss. 1988. A soluble recombinant polypeptide comprising the amino-terminal half of the extracellular region of the CD4 molecule contains an active binding site for human immunodeficiency virus. Proc. Natl. Acad. Sci. USA. 85:2357-2361.

89. Deen, K. C., J. S. McDougal, R. Inacker, W. G. Folena, J. Arthos, J. Rosenberg, P. J. Maddon, R. Axel, and R. W. Sweet. 1988. A soluble form of CD4 (T4) protein inhibits AIDS virus infection. Nature (Lond.). 331:82-84 